\section{Cameroon disaster}

\section{Carbon dioxide blamed \\ Washington}

US INVESTIGATORS at Lake Nios, Cameroon, where 1,700 people were killed by toxic gases on 21 August, believe the disaster was similar to one that occurred in Lake Monoun, also in Cameroon, in 1984, which killed 37 people, according to the State Department Office of Disaster Assistance. There it is thought large quantities of carbon dioxide were released from the lake bottom. Both lakes are set in deep craters, and if the parallel proves correct there could be important implications for geochemically similar lakes in the area, including Lake Kivu.

Among the teams sent from the United States are limnologists, geochemists pathologists and vulcanologists. Also in Cameroon is Harold Sigurdsson of the University of Rhode Island, who studied the Lake Monoun event. He and his colleagues concluded that carbon dioxide, possibly contaminated with other unidentified gases, was released following a disturbance of the lake bottom triggered by a landslide, perhaps caused by a minor earthquake. The carbon dioxide is thought to have slowly seeped from cold volcanic vents and accumulated over many years in high concentration, partly as bicarbonate, in the hypolimnion, along with ferrous ions reduced from siderite deposited in the lake by wind-blown loess. Nucleation points for the saturated solution were provided by the bottom disturbance and the gas came out of solution. Sigurdsson estimated that carbon dioxide was present in the hypolimnion at a pressure equivalent to 10 atmospheres; carbon-14 analysis showed 90 per cent of the carbon to be of volcanic origin.

Some observations of the bodies both at Monoun and Nios suggest that other gases may also have been present. Some descriptions speak of reddish skin burns and foaming at the nose and mouth that would not have been caused by carbon dioxide. Vegetation was also bleached, although clothing was unaffected. Sigurdsson and colleagues excluded sulphuric acid from oxidised hydrogen sulphide as a cause because it was virtually undetectable on the lake and because sulphuric acid usually causes black, rather than red, skin burns. Nitric acid may have been formed from oxidation of ammonia. The US teams will be taking samples from the water at different depths as well as from the atmosphere, and measuring temperature profiles. Pathologists may exhume some bodies for examination; details will be presented to the US ambassador in Cameroon sometime this week or next.

Tim Beardsley

Museums

\title{
Science with a touch of magic
}

WhAT is Richard Gregory, head of the planes) up in the air.

Brain and Perception Laboratory at the University of Bristol, doing bent over a snooker (pool) table? And how is it he never misses a shot?

Closer inspection will reveal that he has given himself an advantage - the inside of the table is elliptical. That means that if two balls are placed at the foci of the ellipses, the two will always collide whatever direction you hit one of them in.

The snooker table is one exhibit from Gregory's new museum, the Exploratory,

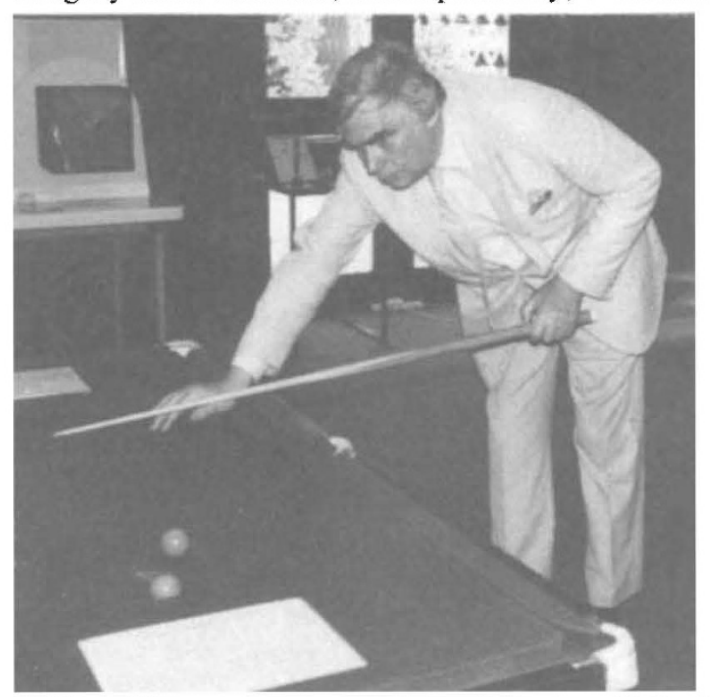

Then there is a set of mirrors to lead you to a solution to the old paradox of why you look left/right reversed in a mirror but not upside-down. The answer is simple and difficult - according to Gregory, among those who have it wrong are Plato, Lucretius and Kant (and Martin Gardner in The Ambidextrous Universe.) The "exploratory" answer: that mirrors allow us to see the front of opaque objects although we are behind them: and the reversal is produced by the rotation of the object to face the mirror. You can try it with a book in front of a mirror: turn a page facing you to face the mirror either by turning it around or by turning it over. The latter produces no left/right reversal.

Dozens of exhibits force even trained scientists to think twice. Among them, Gregory himself is as excited as if he too is seeing them for the first time.

But how are children going to react? The full-size 20,000 square foot "Exploratory - Hands on Science Centre" will be receiving several school parties every day. Will they too recognize that "science has its own magic"? The Exploratory's director, James

which will open next month and from which a selection of exhibits are being previewed at this week's meeting of the British Association for the Advancement of Science in Bristol. Other than the Exploratorium in San Francisco, there is nothing quite like the new museum. It is a place for people to explore: it is not exhibits that do things when people press buttons, but people who do things with the exhibits until explanations emerge.

Many exhibits excite interest by producing effects that are counter-intuitive. For example, two tracks down which model cars can be run have been set up on one wall. One track is straight, the other curved. How many people will be willing to bet that the car on the curved track will reach the finish faster than that on the straight track? And how many believe that if you start a pair of cars off at different points on the curved track they will always arrive at the finish simultaneously wherever you start them from?

Elsewhere, a ball hovers six feet up in the air. It is suspended on a jet of air - no surprise until you see that the air jet is several feet away. Why does the ball not just drop out when the air stream is bent to one side? Some balls dangling on strings nearby and an ordinary hair-dryer give one a chance to explore the Bernoulli effect which keeps the ball (and aero-
Dalgety, who has spent the past fifteen years running a puzzle-manufacturing company, admits to few doubts.

Alun Anderson

- While Bristol's hands-on science exhibition concentrates on brain teasers, London's equivalent is more attuned to catching the imagination of the younger visitor. Under development for several years, "Launch Pad" was officially launched last week at the Science Museum. Most of the 70 exhibits are geared more to technology than to science. And the designers have usually chosen to provide a simple illustration of a principle rather to set a problem.

Among the exhibits that may already have provided the formative experience for the next generation of technologists is the arch bridge: five blocks are arranged on supports to form the arch, the supports are removed and the builder is persuaded to walk over the bridge.

Where problem-solving is in evidence, it is likely to be in the form of assembling a lock and key or water pump from large parts in a transparent casing. The joke exhibit is a standard hot air hand-drier, an adjunct to the several popular exhibits that involve contact with water. Among these is a giant simulated toilet cistern and a miniature flow tank. Peter Newmark 